\title{
Evaluating the Repeatability of Friction Coefficient Measurements and Tactile Perceptions in Skin-Textile Interactions Across Body Regions
}

\author{
Mevra Temel $^{1,2}$ (D) Andrew A. Johnson ${ }^{1}$ (D) Alex B. Lloyd ${ }^{1,2}(\mathbb{D}$
}

Received: 26 August 2021 / Accepted: 30 December 2021 / Published online: 31 January 2022

(c) The Author(s) 2022

\begin{abstract}
Measuring the friction between human skin and textiles is essential to preventing skin-related health problems and wearer discomfort. This study sought to evaluate the repeatability of friction coefficient measurements and tactile perceptions at various human body regions, using a recently developed portable friction measuring device. Using the device, a cotton textile was applied to six test locations. The friction coefficient and tactile perceptions were taken three times, at each test site. The repeatability of friction coefficient was excellent with ICC of $0.91 \pm 0.05$ for static and $0.91 \pm 0.06$ for dynamic friction coefficient, and tactile perception showed good to excellent repeatability. The friction coefficient and tactile perception significantly differed across the body regions ( $p=0.008$ and $p=0.003$, respectively). The chest showed the highest static friction coefficient with $0.90 \pm 0.19$ and dynamic friction coefficient with $0.79 \pm 0.20$, whereas the dorsal forearm with static $0.31 \pm 0.07$ and dynamic $0.25 \pm 0.05$ was the lowest. The ratings of tactile perceptions were independent of friction coefficient when the changes in the coefficient of friction were induced by regional difference, and/or the range of the coefficient of friction values were small. Moreover, skin temperature and friction coefficient correlated positively, whilst cutaneous hydration and friction coefficient did not.
\end{abstract}

Keywords Skin friction $\cdot$ Tactile perception $\cdot$ Repeatability $\cdot$ Clothing design

\section{Abbreviations \\ COF Coefficient of friction \\ ICC Interclass correlation coefficient \\ AU Arbitrary unit}

\section{Introduction}

Friction in skin-textile interaction is directly associated with the potential to generate skin-related health problems, such as tissue deformation and skin damage, or friction blisters [1-4] as well as having an impact on wear comfort [5-8]. For example, movement of fabrics and textile across human skin can cause skin displacement due to static friction, rubbing

Alex B. Lloyd

a.lloyd@lboro.ac.uk

1 School of Design and Creative Arts, Loughborough University, Loughborough, UK

2 Environmental Ergonomics Research Centre, Loughborough University, Loughborough, UK due to dynamic friction, as well as simultaneous changes in the judgement of feel and comfort of clothing via differences in roughness, stickiness, discomfort, and pleasantness sensations [9].

The movement of fabrics in contact with the skin arises when the applied force exceeds the frictional resistance, and this movement creates friction force and a tactile perception of friction. The friction and tactile perception are influenced by the variation of skin physiological and physical properties over the human body, such as skin temperature, hydration, skin thickness, roughness, elasticity, the density of sweat glands, as well as mechanoreceptor distribution [10-13]. Therefore, skin friction coefficient could vary across the different regions of the human body [14-23] and tactile perception might therefore be different across the various regions of the human body. However, there has been no detailed investigation about tactile perception to textiles across different body regions.

To be able to understand friction behaviour and tactile perception during the skin-textile interaction at the various regions of the human body, a portable and easily usable measuring device is essential. Different types of devices 
have previously been used to measure the friction behaviour of human skin [18, 22, 24-27], but these have limitations that prevent to complete examination of friction coefficient and tactile perception across body regions. Because of this, a new portable device, measuring friction coefficient between skin and different types of textiles, was designed and evaluated by Temel et al. [28]. This study introduced the product design specifications, demonstrating that the new device measured friction coefficient between textile and surrogate skins surface materials with an excellent level of repeatability. However, it remains to be investigated whether this device has the same level of repeatability during in vivo testing across different regions of human skin, compared with objective testing on surrogate skin.

Therefore, six research hypothesises were examined in the presented study: 1 . The skin measured friction coefficient to textile would vary across the six human body regions, 2 . The skin friction coefficient across the six body regions would be measured using the newly designed device with good to excellent repeatability, 3 . The associated tactile perception to textiles would vary across the six body regions, 4 . The tactile perception across the six body regions would be assessed using the newly designed device with good to excellent repeatability, 5 . There would be a relationship between skin friction coefficient and tactile perception when the changes in the coefficient of friction are induced by regional difference, and finally, 6 . The physiological measurements, skin temperature and hydration, would influence measurement of skin friction coefficient.

\section{Method}

\subsection{Equipment}

The portable handheld device introduced by Temel et al. [28] was used in this study. Briefly, the device measures the friction coefficient between skin and textiles (e.g., cotton, polyester, silk), as well as objectively assessing regional perception using the localised sensory texting methods [29]. This device works by reciprocating movement, where a superior direction (from feet to head) is presented as a positive value, whilst an inferior direction (from head to feet) of the probe is presented as a negative value. Fig. 1 illustrates a typical friction measurements output between the skin and textile. The dashed line shows the applied normal force; the line indicates the measured friction force in Fig. 1 (top), and the line in Fig. 1 (bottom) indicates the friction coefficient between real human skin and textiles. The average of the peak points $\left(a_{1}, a_{2}, \ldots, a_{10}\right)$ in the friction coefficient line in the positive part is considered a superior friction coefficient, and the mean of the stable points $\left(b_{1}, b_{2}, \ldots, b_{10}\right)$ in the friction coefficient line in the positive part is taken as a superior
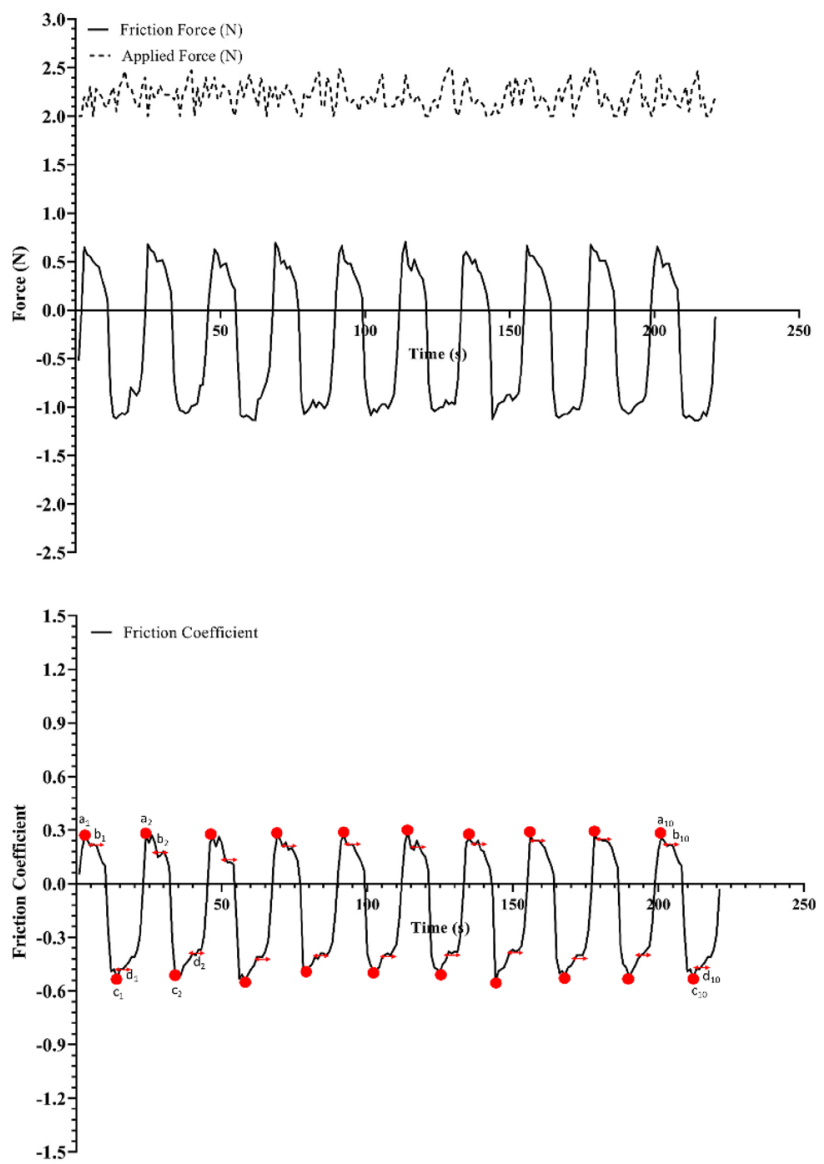

Fig. 1 Typical friction measurement outputs (the data of forearm test region) for normal and fiction force (top) and friction coefficient (bottom)

dynamic friction coefficient as shown in Fig. 1 (bottom). The mean of the peak points $\left(c_{1}, c_{2}, \ldots, c_{10}\right)$ in the friction coefficient line in the negative part is considered an inferior static friction coefficient, and in the negative part of the mean of stable points $\left(d_{1}, d_{2}, \ldots, d_{10}\right)$ is taken as an inferior dynamic friction coefficient as seen in Fig. 1 (bottom). Full technical details of the portable friction measurement device are described in Temel et al. [28].

\subsection{Contact Material}

In this study, knitted - single jersey contact material was a pre-shrunk $100 \%$ cotton sample. The thickness, weights and surface roughness, measured using the Kawabata Evaluation System, where samples measured $0.62 \mathrm{~mm}, 140 \mathrm{~g} / \mathrm{m}^{2}$ and $3.7 \mu \mathrm{m}$, respectively [30]. Each textile sample measured $80 \times 80 \mathrm{~mm}$ in length and width, with a virgin textile sample used every three applications. Prior to measuring friction coefficient, control friction coefficient measurements were taken with contacting surrogate skin to ensure that each textile attached to the probe was in the same condition with 
$0.25 \pm 0.01$ of the static and $0.16 \pm 0.01$ of the dynamic friction coefficients.

\subsection{Participants}

Ten university students, three males and seven females, $(22.3 \pm 2.9$ years, $65.31 \pm 7.62 \mathrm{~kg}, 171.3 \pm 9.1 \mathrm{~cm}$, $24.4 \pm 5.6 \%$ body fat) of Western European origin volunteered to participate in the study. Inclusion criteria was non-smoker, as well as free from cardiovascular, musculoskeletal, cutaneous, and metabolic diseases, or any sensoryrelated disorders. For a period of $24 \mathrm{~h}$ before each trial, participants were asked not to consume caffeine or alcohol, along with refraining from consuming food for two hours prior trial. The study design was approved by the Loughborough University Ethics Committee (ECC/AJ2) and was conducted within the confines of the World Medical Association Declaration of Helsinki for medical research using human participants, except for registration in the database.

\subsection{Test Protocol}

On arrival to the laboratory, all experimental procedures were fully explained to the participants verbally, as well as through a participant information sheet, before obtaining written informed consent, and completing a health screening questionnaire. Female participants were asked to wear a bra and shorts, whilst male participants were requested to have just shorts during the trials. Pre-test measurements included height, body mass (Mettler Toledo Kcc150, Mettler Toledo, Leicester, UK), and body fat percentage (Tanita Corporation, Tokyo, Japan). Following body composition measurements, participants entered an environmental control chamber (custom designed by TIS Services, UK) at $25^{\circ} \mathrm{C}$ and $\% 50$ RH. Wireless temperature loggers (I-Buttons, Maxim, San Jose, USA) administered at four skin sites across the upper chest and triceps on the left-hand side of the body, as well as on the anterior thigh and calf of the right-hand side of the body. Participants were asked to lay supine on a medical bed and were unable to see the application of the friction device to prevent any bias. A 10-min baseline period was used to familiarise participants with all experimental equipment and subjective scales, as shown in Fig. 2.

To assess the perception of the applied fabric texture, i.e. roughness and smoothness, an ordinal bipolar balanced scale was used [30]; whilst to assess user perception of fabric stickiness, i.e. slipperiness and stickiness, a sevenpoint bipolar scale was used by modifying the scales used in Hollins et al. [31]. A bipolar, balanced ordinal scale was used to assess the pleasantness sensation of the tested fabric samples [30]. A five-anchor visual scale was used to indicate discomfort (regional and whole body), which ranges from "Extremely Uncomfortable" to "Comfortable" [32]. Differential numerical values were used for hedonic scales (discomfort, pleasantness) vs sensorial scales (texture, stickiness) to (a) limit cross-referencing bias between hedonic and sensorial scales (i.e., textile and pleasantness); and (b) to encourage participants to focus on the verbal anchors only, rather than making numerical value judgements. Participants were informed about a subjective reference point equating to very rough (the feel of dry wool); very smooth (the feel of dry silk), and very sticky (where the probe does not move on the skin at all); very slippery (where the probe moves on the skin without any resistance).

Before each application, the local skin temperature was measured using a single spot infrared thermometer (FLUKE 566, Fluke Corporation, USA), whilst cutaneous water content in epidermal and stratum corneum skin layers was measured using a dielectric moisture meter (MoistureMeterEpid and MoistureMETESC Compact, Delfin Technologies). The skin was not treated or cleaned in a specific way, as cleaning or treating the skin just before measuring the skin would likely influence the skin friction results. Also, the presence of hair was not visible across
Fig. 2 Texture, stickiness, discomfort, and pleasantness scales used in the experiment
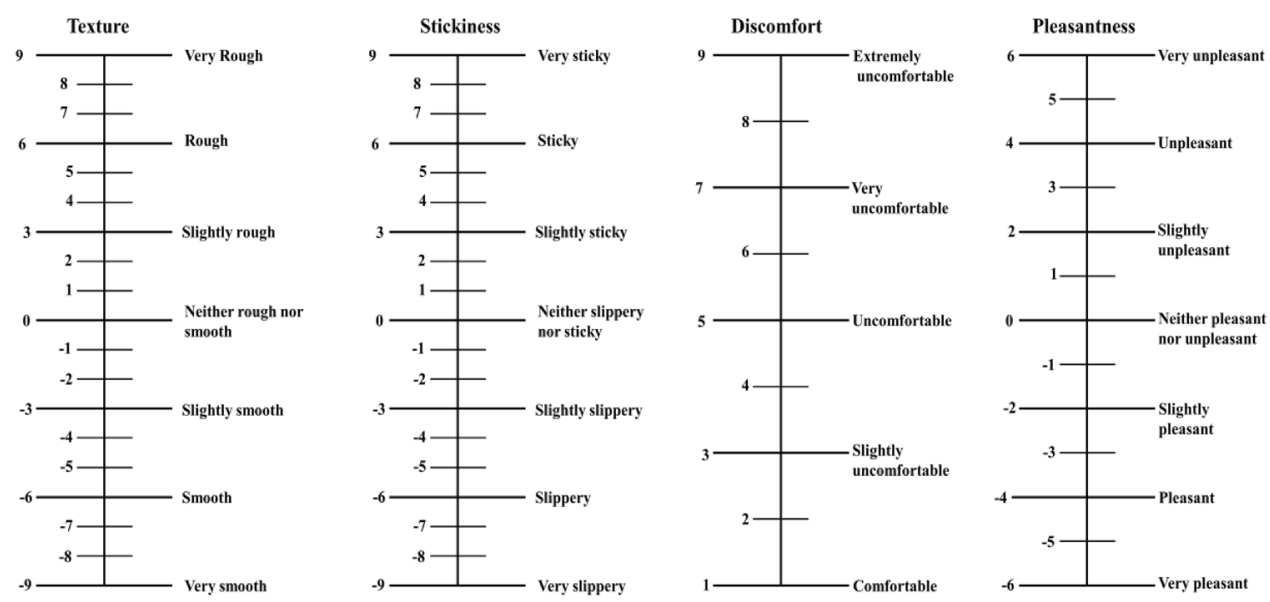
the tested regions except for the dorsal forearm in both female and male participants. Following such measurements, the friction probe with the attached $100 \%$ cotton textile was applied with a normal force of $2 \pm 0.5 \mathrm{~N}$, with a fixed velocity of $0.04 \mathrm{~m} / \mathrm{s}$ (approximately in the middle of pleasantness range [33]), over a $40 \mathrm{~mm}$ moving surface for all six selected test body areas, as illustrated in Fig. 3, using a mixed counterbalanced order.

For all applications, the probe was applied to the skin for a period of 10s. At the end of each episode, the friction coefficient in skin-textile interaction was taken, and participants were asked to rate their tactile perception starting with texture, then stickiness, then discomfort and lastly pleasantness (Fig. 2). This test process was repeated three times to ascertain the repeatability. After the first set in which six body regions were tested following a mixed counterbalanced order, the second set was started in which test procedure was repeated. Finally, the third set was completed using same method. The friction device was replaced according to body regions between the applications, i.e., the measures of skin friction coefficient and perception scores were not taken back-to-back for each body regions. The experiment set up is shown in Fig. 4.

Also, the internal body temperature of each participant was taken in $10 \mathrm{~min}$ intervals throughout the duration of the study using an aural thermometer (Braun Thermo Scan ${ }^{\circledR}$ PRO 6000, Helen of Troy, USA).

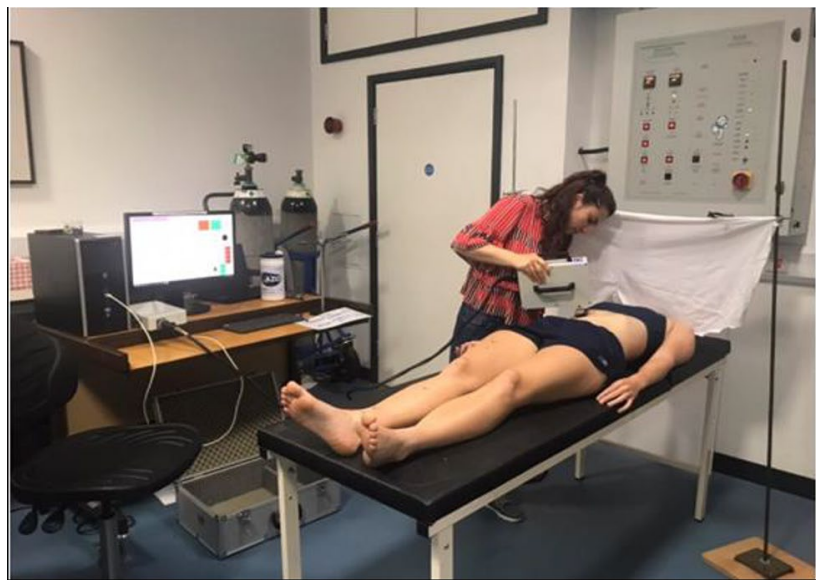

Fig. 4 The experiment set-up

\subsection{Data Analysis}

The normal force, friction force, and friction coefficient were measured and saved, then exported into Microsoft Excel. An example trace can be found in Fig. 1. After completing all tests, data were processed with MATLAB (version R2011b; The MathWorks Inc. Massachusetts, USA).

The normality of all data distributions was confirmed using the Kolmogorov Smirnov test, following which parametric statistics were applied. Differences in friction coefficient and tactile perception across six different body regions
Fig. 3 The name and description of each measurement of the test body areas

\begin{tabular}{|l|l|}
\hline Name & Description \\
\hline Volar Forearm & A posterior point halfway distal between the antecubital fossa and carpus. \\
\hline Chest & A point halfway distance between the nipple and shoulder line. \\
\hline Torso & At a point that intersects between a) $10 \mathrm{~cm}$ lateral of the midsternal line and b) $10 \mathrm{~cm}$ below of the inframammary line. \\
\hline Dorsal Forearm & An interior point halfway distal between the antecubital fossa and carpus. \\
\hline Upper Back & The point is $5 \mathrm{~cm}$ lateral to the point in the back midline which is $10 \mathrm{~cm}$ inferior to cervical vertebra. \\
\hline Lower Back & The point is $25 \mathrm{~cm}$ inferior to upper back measuring point. \\
\hline
\end{tabular}


were analysed using one-way repeated measures of ANOVA. When a significant main effect was found, Tukey's post hoc analyses were performed to investigate pairwise comparisons of the tested regions. The repeatability of static and dynamic friction coefficient, as well as tactile perception, were analysed using the interclass correlation coefficient (ICC), describing how strongly units in the same group resemble each other [34]. Paired-sample $t$ tests were performed on the mean skin temperature and aural temperature to assess the difference between the start and the end of each session. Pearson correlation coefficients were used to assess the correlation between the friction coefficient and tactile perception, and to investigate the relationship between physiological measurements (local skin temperature and hydration), and the friction coefficient. The superior direction skin friction coefficients were used for data analysing and presenting herein; however, both superior and inferior skin friction coefficient data produced similar conclusions. Previous research has presented the data of the superior direction $[5,35,36]$, allowing direct comparison of the results.

\section{Results}

\subsection{Body Temperature, Skin Temperature and Skin Hydration}

The results showed that mean skin temperature and aural body temperature did not significantly change through the study $\left(32.6 \pm 0.4{ }^{\circ} \mathrm{C} ; 36.8 \pm 0.2{ }^{\circ} \mathrm{C}, p=0.35\right.$, respectively). Local skin temperature, hydration-stratum corneum and epidermal level (\%) measured were significantly different across the six body areas $(p<0.001, p=0.011$ and $p=0.004)$. The data are provided in Table 1.

\subsection{Skin Friction-Regional Differences}

The static and dynamic friction coefficient significantly varied across the six body regions ( $p=0.008$ and $p=0.003$, respectively). However, Turkey's multiple comparison test demonstrated that some regions were not statically different skin friction coefficient from others shown in Fig. 5. The chest showed the highest static friction coefficient of
Table 1 The mean value and significance levels of the multiple comparisons for the 6 skin sites are reported for local skin temperature, local skin hydration-stratum corneum LSkH-SC (au) and local skin hydration epiderma LSkH-E $(\%)$

\begin{tabular}{|c|c|c|c|c|c|c|c|}
\hline & Values & Volar forearm & Chest & Torso & Dorsal forearm & Upper back & Lower back \\
\hline \multicolumn{8}{|l|}{ Volar forearm } \\
\hline $\operatorname{LSkT}\left({ }^{\circ} \mathrm{C}\right)$ & $32.0 \pm 0.9$ & - & & & & & \\
\hline LSkH-SC (au) & $11.9 \pm 5.3$ & - & & & & & \\
\hline LSkH-E (\%) & $39.7 \pm 8.3$ & - & & & & & \\
\hline \multicolumn{8}{|l|}{ Chest } \\
\hline $\operatorname{LSkT}\left({ }^{\circ} \mathrm{C}\right)$ & $33.9 \pm 0.7$ & $* *$ & - & & & & \\
\hline LSkH-SC (au) & $24.4 \pm 5.9$ & & - & & & & \\
\hline LSkH-E (\%) & $41.5 \pm 4.4$ & $* *$ & - & & & & \\
\hline \multicolumn{8}{|l|}{ Torso } \\
\hline $\operatorname{LSkT}\left({ }^{\circ} \mathrm{C}\right)$ & $33.2 \pm 0.6$ & & $* *$ & - & & & \\
\hline LSkH-SC (au) & $15.5 \pm 2.3$ & & & - & & & \\
\hline LSkH-E (\%) & $39.6 \pm 2.5$ & & $*$ & - & & & \\
\hline \multicolumn{8}{|l|}{ Dorsal forearm } \\
\hline $\operatorname{LSkT}\left({ }^{\circ} \mathrm{C}\right)$ & $33.4 \pm 0.7$ & & & & - & & \\
\hline LSkH-SC (au) & $18.2 \pm 2.6$ & & & & - & & \\
\hline LSkH-E (\%) & $39.1 \pm 5.5$ & & $*$ & & - & & \\
\hline \multicolumn{8}{|l|}{ Upper back } \\
\hline $\operatorname{LSkT}\left({ }^{\circ} \mathrm{C}\right)$ & $33.9 \pm 0.4$ & $* *$ & & $* *$ & & - & \\
\hline LSkH-SC (au) & $24.7 \pm 6.9$ & & $*$ & $* * *$ & $* *$ & - & \\
\hline LSkH-E (\%) & $49.1 \pm 4.8$ & $*$ & & $*$ & & - & \\
\hline \multicolumn{8}{|l|}{ Lower back } \\
\hline $\operatorname{LSkT}\left({ }^{\circ} \mathrm{C}\right)$ & $33.5 \pm 0.7$ & & & & & & - \\
\hline LSkH-SC (au) & $20.7 \pm 6.2$ & & & & & $* *$ & - \\
\hline LSkH-E (\%) & $44.5 \pm 5.5$ & & & & & & - \\
\hline
\end{tabular}

LSkT $\left({ }^{\circ} \mathrm{C}\right)$, local skin temperature; LSkH-SC (au), local skin hydration-stratum corneum; LSkH-E $(\%)$, local skin hydration-epiderma

$* p<0.05 ; * *<<0.01 ; * * * p<0.001$ 
Fig. 5 The box and whisker graphs show the superior static and dynamic skin friction coefficient across the six body regions taken from ten participants. Ten out of the fifteen comparisons were significantly different in their static and dynamic skin friction coefficient. However, the rest of them were non-significantly different, represented in the graph

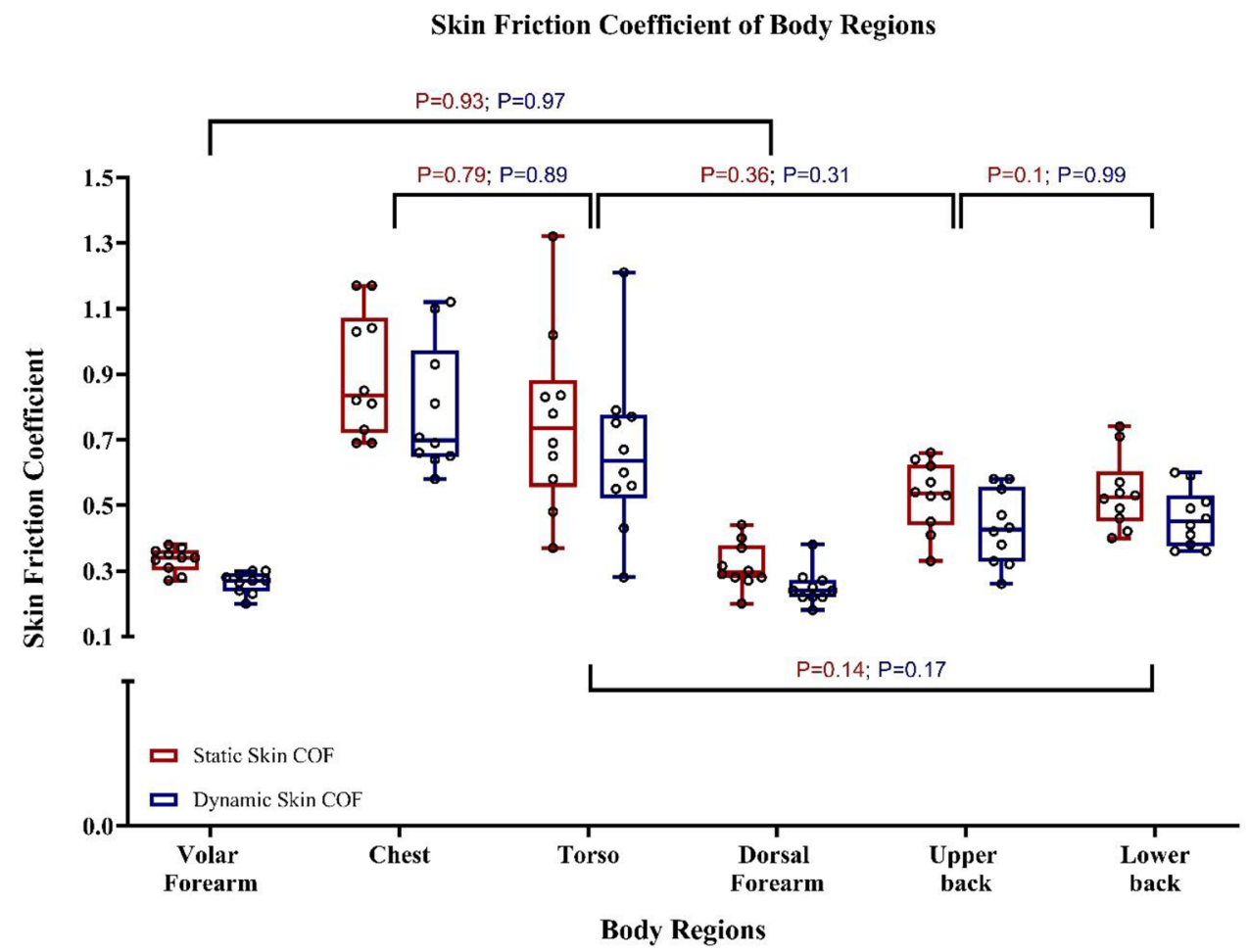

Table 2 The intraclass correlation coefficient outcomes for the static and dynamic skin friction coefficient across the body regions

\begin{tabular}{lll}
\hline \multicolumn{2}{l}{ Friction coefficient repeatability (ICC) } \\
\hline & Static COF & Dynamic COF \\
\hline Volar forearm & 0.85 & 0.82 \\
Chest & 0.89 & 0.89 \\
Torso & 0.94 & 0.97 \\
Dorsal forearm & 0.98 & 0.95 \\
Upper back & 0.85 & 0.97 \\
Lower back & 0.94 & 0.86 \\
\hline
\end{tabular}

$0.90 \pm 0.19$ and dynamic friction coefficient of $0.79 \pm 0.20$ whilst the lowest one was dorsal forearm with static of $0.31 \pm 0.07$ and dynamic of $0.25 \pm 0.05$.

\subsection{Skin Friction-Repeatability}

The static and dynamic friction coefficient across the sixbody regions and their repeatability (ICC) are presented in Table 2 . The repeatability (ICC) of the novel device was $0.91 \pm 0.05$ for static and $0.91 \pm 0.06$ for dynamic friction coefficient.

\subsection{Tactile Perception-Regional Differences}

There was a statistically significant difference across the body test regions in texture perception $(p<0.001)$ as shown in Fig. 6. Turkey's multiple comparison test showed that body regions in the front side (volar forearm, chest and torso) were not significantly different from each other and also in the backside (dorsal forearm, lower and upper back). However, the test regions on the front side were significantly different from those on the backside.

There was a statistically significant difference between the test areas in stickiness perception $(p=0.002)$ as seen in Fig. 6, but according to Turkey's multiple comparisons test, only the lower back and chest were different from each other. The pleasantness perception of textile statistically varied across the six tested areas $(p<0.001)$ as illustrated in Fig. 6, but according to Turkey's multiple comparisons test, only the volar forearm and dorsal forearm were different from each other. Moreover, people perceived their comfort perception differently across the tested regions $(p<0.001)$ as displayed in Fig. 6. However, Turkey's multiple comparison test showed that body regions on the front side (volar forearm, chest and torso) were not significantly different from each other and also those on the backside (dorsal forearm, lower and upper back) did not vary from each other. 

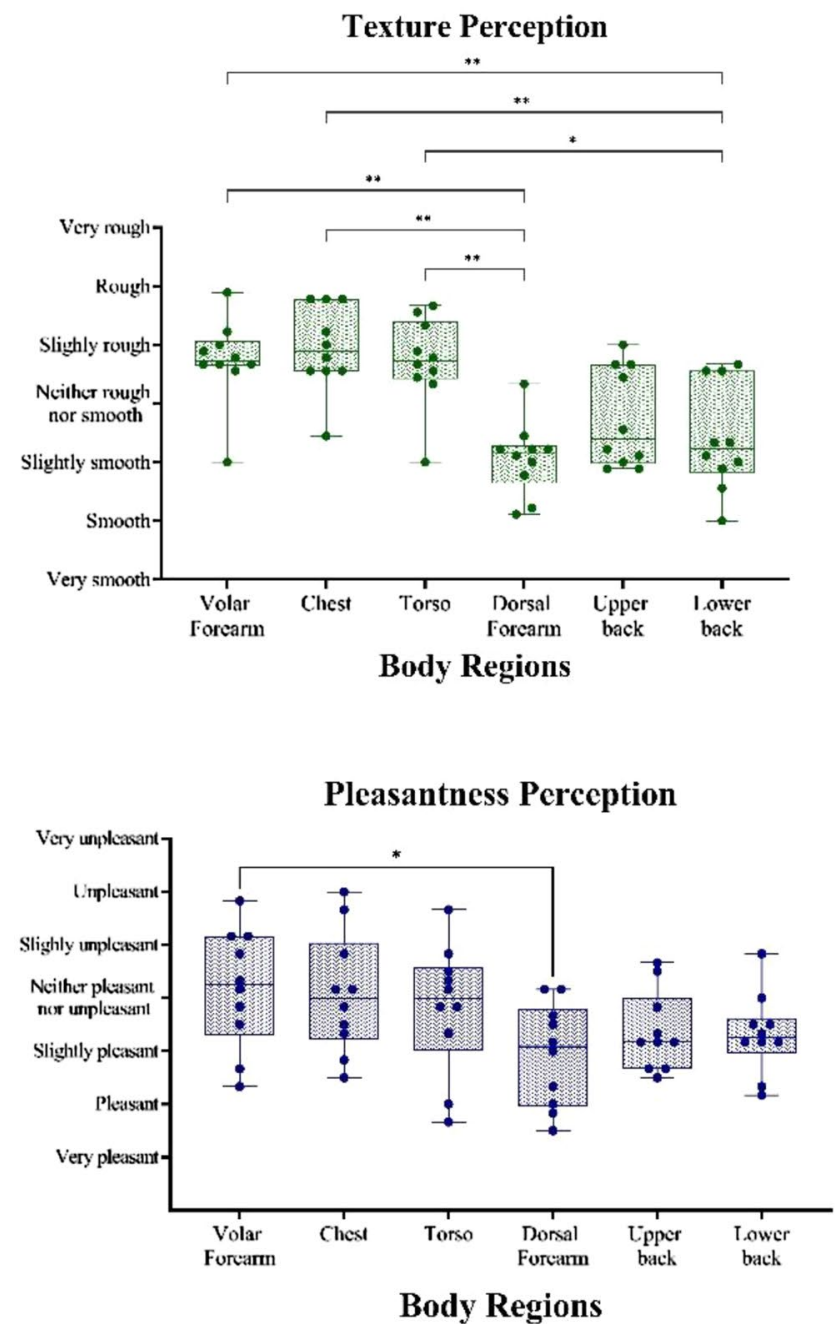
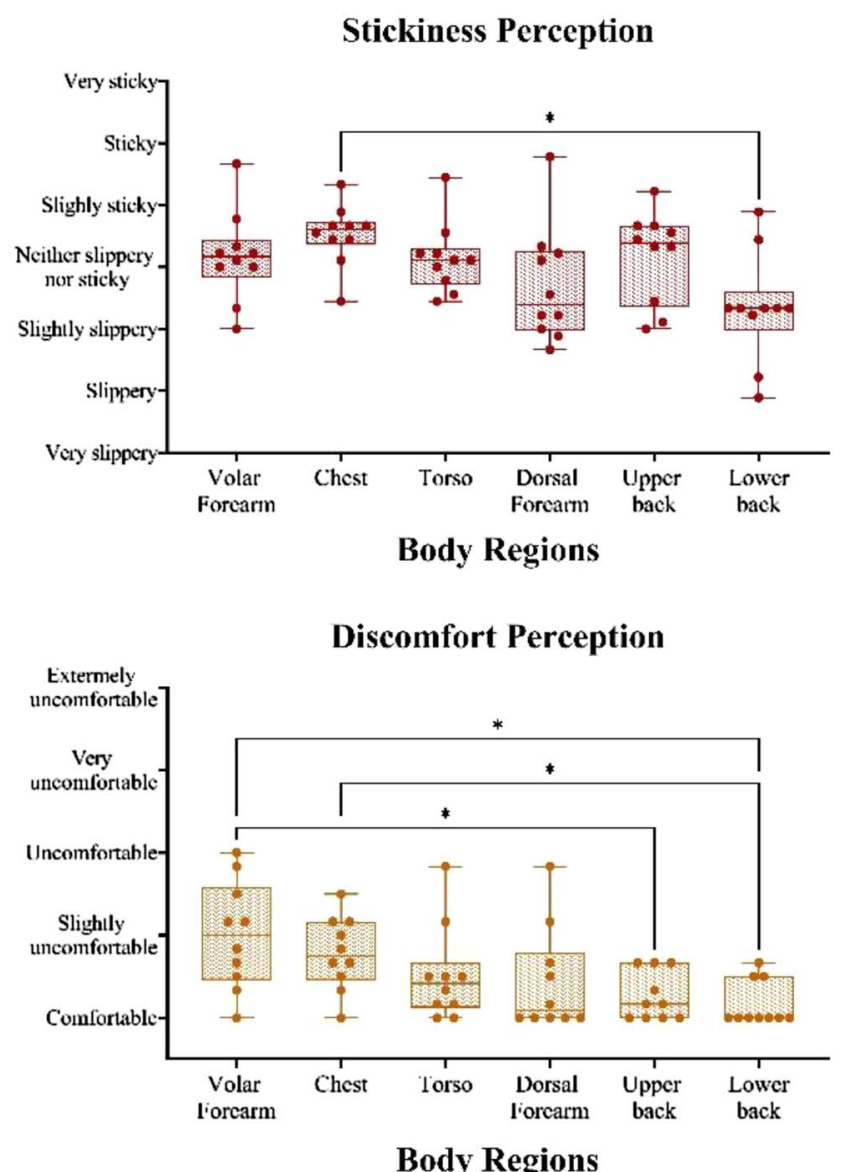

Fig. 6 The box and whisker graphs show the tactile perceptions, texture, stickiness, and discomfort, across the six body regions. Significant differences shown with $* p<0.05 ; * *<<0.01 ; * * p<0.001$

Table 3 The intraclass correlation coefficient outcomes for the tactile perceptions across the six body regions

\begin{tabular}{lllll}
\hline \multicolumn{4}{l}{ Tactile perception repeatability (ICC) } & \\
\hline & $\begin{array}{l}\text { Texture } \\
\text { percep- } \\
\text { tion }\end{array}$ & $\begin{array}{l}\text { Stickiness } \\
\text { perception }\end{array}$ & $\begin{array}{l}\text { Discomfort } \\
\text { perception }\end{array}$ & $\begin{array}{l}\text { Pleasantness } \\
\text { perception }\end{array}$ \\
\hline Volar forearm & 0.95 & 0.88 & 0.81 & 0.85 \\
Chest & 0.96 & 0.78 & 0.84 & 0.88 \\
Torso & 0.95 & 0.82 & 0.86 & 0.84 \\
Dorsal forearm & 0.94 & 0.88 & 0.88 & 0.87 \\
Upper back & 0.94 & 0.96 & 0.86 & 0.89 \\
Lower back & 0.92 & 0.93 & 0.96 & 0.82 \\
\hline
\end{tabular}

\subsection{Tactile Perception-Repeatability}

The ICC values for the repeatability of tactile perceptions are presented in Table 3. The mean of six-body regions ICC of tactile perceptions including texture, stickiness, discomfort, and pleasantness were $0.94 \pm 0.02,0.88 \pm 0.06$, $0.87 \pm 0.05$ and $0.86 \pm 0.02$, respectively.

\subsection{Relationship Between Skin Friction Coefficient and Tactile Perceptions}

The results suggested that the ratings of tactile perception (texture, stickiness, discomfort, and pleasantness) were independent on static friction coefficient $(p=0.06, p=0.14$, $p=0.2$, and $p=0.4$, respectively), and dynamic friction coefficient ( $p=0.06, p=0.1, p=0.3$, and $p=0.1$, respectively) when the changes in the coefficient of friction were induced 
Fig. 7 The relationship between skin temperature and static (a) and dynamic (b) skin friction coefficient
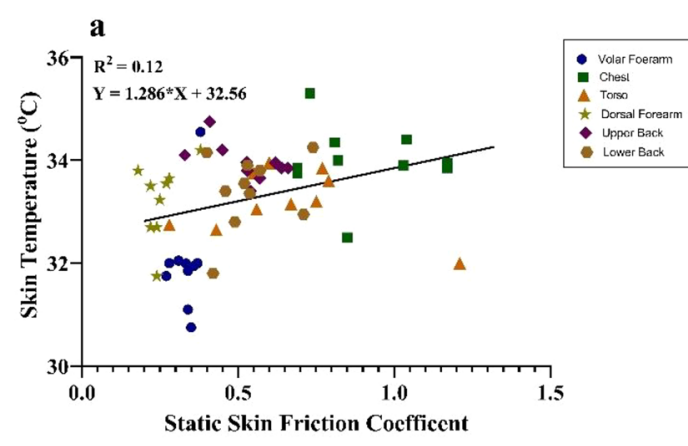

b

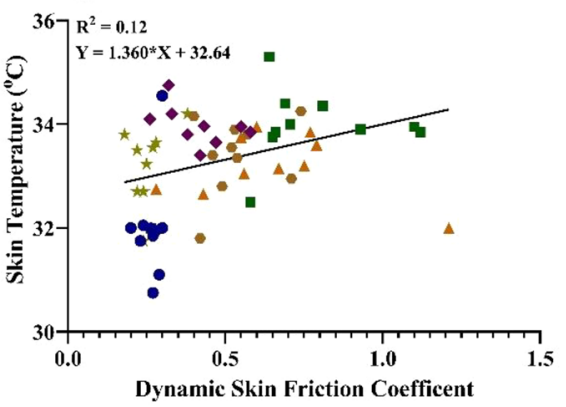

by regional difference, and/or the range of the coefficient of friction values were small.

\subsection{Relationship Between Local Skin Temperature and Hydration, and Skin Friction Coefficient}

There was a relationship between skin temperature and static and dynamic skin friction coefficient. $\left(p=0.006 ; r^{2}=0.12\right.$ and $p=0.007 ; r^{2}=0.12$ ) as seen in Fig. 7. Hydration level of both stratum corneum and epiderma did not impact static ( $p=0.37$ and $p=0.22$, respectively) and dynamic skin friction coefficient ( $p=0.54$ and $p=0.19$, respectively).

\section{Discussion}

This study aimed to investigate the repeatability of friction coefficient measurements and tactile perceptions at various regions of the human body, using a recently developed custom-made friction measuring device and the effects of skin physiological features on skin friction coefficient, and tactile perceptions. According to the aims, six hypotheses are discussed:

\subsection{Hypothesis 1-The Skin Friction Coefficient Would Vary Across the Six Body Regions}

Human skin is the biggest organ that covers the body to protect against external threats [37]. It is known that skin temperature [38] and sweat production [39, 40] vary across body regions. However, knowledge is limited on understanding the regional skin friction coefficient variation across the body. Although a small number of studies have investigated that the skin friction coefficient varied across the tested body sites [14-23], the friction coefficient in skin-textile interaction has not been investigated across multiple body regions. In this study, the friction coefficient during dynamic interaction between skin and textile was measured across six different body locations. Results from this investigation showed that the friction coefficient in skin-textile interaction varied considerably across the anatomical regions $(p<0.01)$ in agreement with hypothesis 1 . The average static and dynamic friction coefficients were obtained in order from the highest to lowest as chest, torso, lower back, upper back, volar forearm, and dorsal forearm. It could be suggested that hairs at the dorsal forearm were a potential contributing factor for the lower friction coefficient in skin-textile interaction established, at this location in comparison with the volar forearm [14, 41], and hairs on the skin may lead to a decreasing contact surface area like surface roughness, which has been shown to weaken adhesion between the two surfaces [35]. The skin can be considered as a viscoelastic material so that physical features of the skin may influence skin friction behaviour via changes in skin elasticity, as well as the amount of fat and muscle tissue under the dermis layer.

\subsection{Hypothesis 2-Skin Friction Coefficient Across the Six Body Regions Would be Measured Using the Newly Designed Device with Good to Excellent Repeatability}

Although the repeatability of the novel device measuring skin friction was evaluated using the objective testing method in Temel et al. [28], evaluating the repeatability of the novel friction device in vivo and tactile perceptions were remained to be investigated. Overall measuring the friction coefficient is often a challenging activity due to the nonflat surface of the human body. Therefore, this study was evaluated the repeatability of friction coefficient and tactile perceptions across the six tested body areas, providing a significant contribution to support future friction-based in vivo evaluation activities. In agreement with hypothesis 2 , the results of the present study showed that the repeatability (ICC) of static and dynamic friction coefficient values were $0.91 \pm 0.05$ and $0.91 \pm 0.06$, respectively, suggesting excellent repeatability [34]. Although the day-to-day reproducibility was not examined in this study, Temel et al. investigated this in the previous experiment, and observed very consistent day-to-day reproducibility/ reliability using surrogate skins [28]. 
As previously noted, a small number of hand-made devices have been used to measure skin friction in previous studies. However, such devices were not evaluated concerning their in vivo repeatability.

\subsection{Hypothesis 3-Tactile Perception Would Vary Across the Six Body Regions}

Comfort is based on the human sensory response to clothing materials [42]. The type of sensation depends heavily on the skin-textile interaction, and the sensory receptors that are being triggered [43]. Although much research has been conducted to understand tactile perception when skin and textiles interact $[9,30,44,45]$, there has been limited research in assessing tactile perceptions across various body regions. As such, within this study regional tactile perceptions were examined under the dynamic textile and skin interaction. Results from this study showed that regional texture, stickiness, discomfort, and pleasantness perceptions were statistically different across the six body locations. As presented in Fig. 6, the front side of the body (volar forearm, chest and torso) were more sensitive in comparison to the backside of the body (dorsal forearm, upper back and lower back). Also, participants felt slightly unpleasant and uncomfortable on the front side compared to the backside. A possible explanation for this might be the variation of mechanoreceptor distribution over the body [10-13, 46]. Moreover, each spinal nerve carries somatic sensory information from a specific area of the skin on the surface of the body which is called a dermatome to the central nervous system through the spinal cord [47]. The level of transformation of the sensory information from each dermatome might be different. That would be another possible explanation for the regional difference of tactile perception. Whilst this remains to be investigated, it seems plausible that the chest, torso or volar forearm test locations have a greater density of mechanoreceptors in comparison to other test sites. From an evolutionary perspective, another possible explanation is that skin of test location on the front part of the body are more defensive to external danger as they are nearer to inner organs and vessels in compared to test areas on the backside of the body.

\subsection{Hypothesis 4-The Tactile Perception Across the Six Body Regions Would be Assessed Using the Newly Designed Device with Good to Excellent Repeatability}

Tactile perceptions (texture, stickiness, discomfort and pleasantness) were assessed in the current study, where the repeatability of scores of tactile perceptions was assessed. The ICC of tactile perceptions were obtained that texture perception was accepted as having excellent repeatability, whilst the remaining perceptions had a good level of repeatability [34]. As such, it can be concluded that the novel friction device outlined within the research by Temel et al. [28] was also successful in terms of supporting the assessment of tactile perception. Whilst previous research has investigated textile perception under the dynamic skin and textile interaction using a range of equipment configurations $[30,45,48]$, to our knowledge there has been no investigation into the repeatability of ratings of participants' perceptions with an acceptable level of repeatability.

To conclude, the friction measurement device designed and evaluated using objective testing methods by Temel et al. [28], is shown to be successful in reliably measuring skin friction coefficient in vivo and supporting the assessment of tactile perception. In additional to repeatability and reliability investigation, the day-to-day reproducibility of tactile perception assessment carried out by three independent operators using the friction measurement device could be beneficial for future research.

\subsection{Hypothesis 5-There Would be a Relationship Between Skin Friction Coefficient and Tactile Perceptions}

The findings of the present study do not support hypothesis 5 , indicating that tactile perception was not related to friction coefficient across the test body regions when the changes in the coefficient of friction were induced by regional difference, and/or the range of the coefficient of friction values were small. In the literature the correlation between skin friction and tactile perception has previously been reported [5, 44, 49-51]. However, these studies tested various materials having different physical features, e.g., surface roughness to increasing or decreasing the skin friction coefficient. However, the physical attributes of the contact material within this investigation were maintained by employing one type of textile and changing the skin friction coefficient by varying skin parameters such as thickness and elasticity by shifting test body areas. This approach was utilized because it is more representative of real-world scenarios, such as wearing a t-shirt or other garments with the same fabric contacting different parts of the body. On the light of this finding, it shows that tactile perception and skin friction coefficient were distinct phenomena when the changes in skin friction coefficient were induced by regional difference, and/ or the range of the coefficient of friction values were small. It seems likely, therefore, that skin friction is related to physiological features of skin (thickness of skin and elasticity of skin depends on age, gender and ethnicity), physical features of conduct material (thickness of the material, surface finish, roughness and stiffness), and environmental conditions [41, 52-54] whereas tactile perception is related to the distribution or sensitivity of mechanoreceptors within the skin, as noted above. As such, mechanoreceptor distribution over the 
body may go some way to explain variations in tactile perception across the six body location [10-13]. It is important to note that texture perception can be influenced by a variety of cognitive factors, such as beliefs, social and cultural factors, past experiences, and present desires [43], which may be an interesting avenue for future research.

\subsection{Hypothesis 6-Skin Temperature and Hydration Would Influence Skin Friction}

In agreement with hypothesis 6 , the results of the study showed that the skin temperature and skin friction coefficient correlated positively. This finding supports previous research that the adhesion between the skin and contact material is influenced by the temperature of the skin [55]. In presented study, local skin temperature changing was provided by changing different body regions. Although the positive correlation between the skin friction coefficient and local skin temperature was found, another possible parameter could affect this relationship, e.g., the physiological or physical properties of skin such as skin blood flow, skin thickness or skin elasticity.

The outermost layer of the skin is the stratum corneum, which is in contact with the testing material in skin friction measurements. Within the literature, this layer is regarded as the most important layer in terms of skin friction [56, 57]. Therefore, the effect of hydration on skin friction is expected to be more pronounced. However, the findings of the present study do not support hypothesis 6, providing no significant relationship between the hydration level changing by body location and the skin friction coefficient was obtained. Studies within prior literature found that friction coefficient increased with increasing hydration $[5,55$, 58-60]. As such, it must be noted that within these previously published studies the hydration of the skin was artificially increased by applying water to the skin or soaking the skin in water for a certain period or changing environmental conditions, whereas in the present study skin hydration level was varied across a small range.

\section{Conclusion}

The presented study examined six hypotheses underlying skin friction measurements, with key findings demonstrating that:

(1) The skin friction coefficient and tactile perception varied across the six tested regions. The chest location produced the highest friction coefficient whilst the dorsal forearm location produced the lowest during dynamic textile interaction. Also, the participants perceived it to be textile interactions to be rougher on the front of the body, compared to the backside of the body.

(2) The newly established device is capable of successfully measuring the friction coefficient in skin-textile interaction in vivo with an excellent level of repeatability and supports tactile perception assessment activities with a good level of repeatability.

(3) The difference in friction between different body sites was not correlated to the difference in tactile perception between these body sites, providing that tactile perception and skin friction coefficient were distinct phenomena when the changes in the coefficient of friction were induced by regional difference, and/or the range of the coefficient of friction values were small.

(4) The local skin temperature and skin friction coefficient correlated positively, which could be influenced by skin physiological and physical features, but the difference in skin hydration level between various body sites was not correlated to the difference in skin friction coefficient between these body sites

The findings from this work can be useful for product development and to enhance the experience and functionality of products. However, further research is required to establish a complete understanding of the regional variation of skin friction coefficient and tactile perception of textile.

Author Contributions All authors contributed to the study conception and design. Material preparation, data collection and analysis were performed by MT. Manuscript creation was led by MT with input from the co-authors.

Funding This research was financially supported by the Ministry of National Education (the Republic of Turkey) PhD scholarship.

\section{Declarations}

Conflict of interest The authors declare that there are no conflicts of interests within the outlined work.

Open Access This article is licensed under a Creative Commons Attribution 4.0 International License, which permits use, sharing, adaptation, distribution and reproduction in any medium or format, as long as you give appropriate credit to the original author(s) and the source, provide a link to the Creative Commons licence, and indicate if changes were made. The images or other third party material in this article are included in the article's Creative Commons licence, unless indicated otherwise in a credit line to the material. If material is not included in the article's Creative Commons licence and your intended use is not permitted by statutory regulation or exceeds the permitted use, you will need to obtain permission directly from the copyright holder. To view a copy of this licence, visit http://creativecommons.org/licenses/by/4.0/. 


\section{References}

1. Baby, R., Mathur, K., DenHartog, E.: Skin-textiles friction: importance and prospects in skin comfort and in healthcare in prevention of skin injuries. J. Text. Inst. (2020). https://doi.org/ 10.1080/00405000.2020.1827582

2. Knapik, J.J., Reynolds, K.L., Duplantis, K.L., Jones, B.H.: Friction blisters: pathophysiology. Prev. Treat. Sport Med. 20, 136-147 (1995). https://doi.org/10.2165/00007256-19952 0030-00002

3. Baussan, E., Bueno, M., Rossi, R., Derler, S.: Analysis of current running sock structures with regard to blister prevention. Text. Res. J. 83, 836-848 (2013). https://doi.org/10.1177/0040517512 461698

4. Kwiatkowska, M., Franklin, S.E., Hendriks, C.P., Kwiatkowski, K.: Friction and deformation behaviour of human skin. Wear 267, 1264-1273 (2009). https://doi.org/10.1016/j.wear.2008.12. 030

5. Yin, L., Shim, E., DenHartog, E.: A study of skin physiology, sensation and friction of nonwoven fabrics used in absorbent hygiene products in neutral and warm environments. Biotribology. 24, 100149 (2020). https://doi.org/10.1016/j.biotri.2020. 100149

6. Ciesielska-Wróbel, I.L., Van Langenhove, L.: The hand of textiles-definitions, achievements, perspectives-a review. Text. Res. J. 82, 1457-1468 (2012). https://doi.org/10.1177/00405 17512438126

7. Das, A., Alagirusamy, R.: Improving Tactile Comfort in Fabrics and Clothing. Elsevier Masson SAS, Amsterdam (2011)

8. Robertson, A., Lloyd, A., Smith, N.: Skin viability and microvascular function under localised applications of heat and pressure. FASEB J. (2021). https://doi.org/10.1096/FASEBJ.2021.35.S1. 05085

9. Gwosdow, A.R., Stevens, J.C., Berglund, L.G., Stolwijk, J.A.J.: Skin friction and fabric sensations in neutral and warm environments. Text. Res. J. 56, 574-580 (1986). https://doi.org/10.1177/ 004051758605600909

10. McGlone, F., Reilly, D.: The cutaneous sensory system. Neurosci. Biobehav. Rev. 34, 148-159 (2010). https://doi.org/10.1016/j. neubiorev.2009.08.004

11. Goldstein, E.B.: Sensation and Perception. Cengage Learning, Boston (2013)

12. Myles, K., Binseel, M.S.: The Tactile Modality: A Review of Tactile Sensitivity and Human Tactile Interfaces. Army Research Laboratory, Adelphi (2007)

13. Lederman, S.J., Klatzky, R.L.: Haptic perception: a tutorial (2009)

14. Cua, A.B., Wilhelm, K.P., Maibach, H.I.: Frictional properties of human skin: relation to age, sex and anatomical region, stratum corneum hydration and transepidermal water loss. Br. J. Dermatol. 123, 473-479 (1990). https://doi.org/10.1111/j.1365-2133.1990. tb01452.x

15. Ramalho, A., Silva, C.L., Pais, A.A.C.C., Sousa, J.J.S.: In vivo friction study of human skin: influence of moisturizers on different anatomical sites. Wear 263, 1044-1049 (2007). https://doi.org/10. 1016/j.wear.2006.11.051

16. Veijgen, N.K., Masen, M.A., van der Heide, E.: Variables influencing the frictional behaviour of in vivo human skin. J. Mech. Behav. Biomed. Mater. 28, 448-461 (2013). https://doi.org/10. 1016/j.jmbbm.2013.02.009

17. Zhu, Y.H., Song, S.P., Luo, W., Elias, P.M., Man, M.Q.: Characterization of skin friction coefficient, and relationship to stratum corneum hydration in a normal chinese population. Skin Pharmacol. Physiol. 24, 81-86 (2011). https://doi.org/10.1159/000321993

18. Hendriks, C.P., Franklin, S.E.: Influence of surface roughness, material and climate conditions on the friction of human skin. Tribol. Lett. 37, 361-373 (2010). https://doi.org/10.1007/ s11249-009-9530-7

19. Gitis, N., Sivamani, R.: Tribometrology of skin. Tribol. Trans. 47, 461-469 (2004). https://doi.org/10.1080/05698190490493355

20. Derler, S., Gerhardt, L.C., Lenz, A., Bertaux, E., Hadad, M.: Friction of human skin against smooth and rough glass as a function of the contact pressure. Tribol. Int. 42, 1565-1574 (2009). https:// doi.org/10.1016/j.triboint.2008.11.009

21. Cua, A.B., Wilhelm, K.P., Maibach, H.I.: Skin surface lipid and skin friction: relation to age, sex and anatomical region. Skin Pharmacol. Physiol. 8, 246-251 (1995). https://doi.org/10.1159/ 000211354

22. Zhang, M., Mak, A.F.T.: In vivo friction properties of human skin. Prosthet. Orthot. Int. 23, 135-141 (1999). https://doi.org/10.3109/ 03093649909071625

23. Manuskiatti, I.V., Schwindt, D.A., Maibach, H.I.: Influence of age, anatomic site and race on skin roughness and scaliness. Dermatology 196, 392-396 (1998)

24. Gee, M.G., Tomlins, P., Calver, A., Darling, R.H., Rides, M.: A new friction measurement system for the frictional component of touch. Wear 259, 1437-1442 (2005). https://doi.org/10. 1016/j.wear.2005.02.053

25. El-Shimi, A.F.: In vivo skin friction measurements. J. Soc. Cosmet. Chem. 51, 37-51 (1977)

26. Comaish, J.S., Harborow, P.R.H., Hofman, D.A.: A hand-held friction meter. Br. J. Dermatol. 89, 33-35 (1973). https://doi. org/10.1111/j.1365-2133.1973.tb01914.x

27. Veijgen, N.K., Masen, M.A., Van Der Heide, E.: A novel approach to measuring the frictional behaviour of human skin in vivo. Tribol. Int. 54, 38-41 (2012). https://doi.org/10.1016/j. triboint.2012.05.022

28. Temel, M., Lloyd, A.B., Johnson, A.A.: Evaluating the design and repeatability of a novel device to measure friction of mechanical surrogate skins in contact with cotton textiles. Tribol. Lett. 69, 121 (2021). https://doi.org/10.1007/ s11249-021-01502-1

29. Temel, M., Johnson, A.A., Havenith, G., Arnold, J.T., West, A.M., Lloyd, A.B.: An examination of five theoretical foundations associated with localized thermosensory testing. Eur. J. (2021). https:// doi.org/10.1007/s00421-021-04670-z

30. Raccuglia, M., Pistak, K., Heyde, C., Qu, J., Mao, N., Hodder, S., Havenith, G.: Human wetness perception of fabrics under dynamic skin contact. Text. Res. J. 88, 2155-2168 (2017). https://doi.org/ 10.1177/0040517517716905

31. Hollins, M., Faldowski, R., Rao, S., Young, F.: Perceptual dimensions of tactile surface texture: a multidimensional scaling analysis. Percept. Psychophys. 54, 697-705 (1993). https://doi.org/10. 3758/BF03211795

32. Griffiths, I.D., Boyoe, P.R.: Performance and thermal comfort Ergonomics 14, 457-468 (1971). https://doi.org/10.1080/00140 137108931266

33. Ackerley, R., Saar, K., McGlone, F., Backlund Wasling, H.: Quantifying the sensory and emotional perception of touch: differences between glabrous and hairy skin. Front. Behav. Neurosci. 8, 1-12 (2014). https://doi.org/10.3389/fnbeh.2014.00034

34. Koo, T.K., Li, M.Y.: A guideline of selecting and reporting intraclass correlation coefficients for reliability research. J. Chiropr. Med. 15, 155-163 (2016). https://doi.org/10.1016/j.jcm.2016.02. 012

35. Klaassen, M., de Vries, E.G., Masen, M.A.: Friction in the contact between skin and a soft counter material: effects of hardness and surface finish. J. Mech. Behav. Biomed. Mater. 92, 137-143 (2019). https://doi.org/10.1016/j.jmbbm.2019.01.006

36. Klaassen, M., Schipper, D.J., Masen, M.A.: Influence of the relative humidity and the temperature on the in-vivo friction 
behaviour of human skin. Biotribology. 6, 21-28 (2016). https:// doi.org/10.1016/j.biotri.2016.03.003

37. Schepers, R.J., Ringkamp, M.: Thermoreceptors and thermosensitive afferents. Neurosci. Biobehav. Rev. 34(2), 177-184 (2010)

38. Liu, Y., Wang, L., Di, Y., Liu, J., Zhou, H.: The effects of clothing thermal resistance and operative temperature on human skin temperature. J. Therm. Biol. 38, 233-239 (2013). https://doi.org/ 10.1016/j.jtherbio.2013.03.001

39. Smith, C.J., Havenith, G.: Body mapping of sweating patterns in male athletes in mild exercise-induced hyperthermia. Eur. J. Appl. Physiol. 111, 1391-1404 (2011). https://doi.org/10.1007/ s00421-010-1744-8

40. Raccuglia, M., Heyde, C., Lloyd, A., Hodder, S., Havenith, G.: The use of infrared thermal imaging to measure spatial and temporal sweat retention in clothing. Int. J. Biometeorol. (2019). https:// doi.org/10.1007/s00484-019-01701-5

41. Derler, S., Gerhardt, L.C.: Tribology of skin: review and analysis of experimental results for the friction coefficient of human skin. Tribol. Lett. 45(1), 1-27 (2012). https://doi.org/10.1007/ s11249-011-9854-y

42. Barker, R.L.: From fabric hand to thermal comfort: the evolving role of objective measurements in explaining human comfort response to textiles. Int. J. Cloth. Sci. Technol. 14, 181-200 (2002). https://doi.org/10.1108/09556220210437158

43. Kilinc-Balci, F.S.: How Consumers Perceive Comfort in Apparel. Elsevier Masson SAS, Amsterdam (2011)

44. Ramalho, A., Szekeres, P., Fernandes, E.: Friction and tactile perception of textile fabrics. In: Tribology International, pp. 29-33 (2013)

45. Maggie, K.P., Chau, K.H., Kan, C.W., Fan, J.T.: Magnitude estimation approach for assessing stickiness sensation perceived in wet fabrics. Fibers Polym. 19, 2418-2430 (2018). https://doi.org/ 10.1007/s12221-018-8626-9

46. Corniani, G., Saal, H.P.: Tactile innervation densities across the whole body. J. Neurophysiol. 124, 1229-1240 (2020). https://doi. org/10.1152/jn.00313.2020

47. Martini, F.H., Ober, W.C., Nath, J.L., Bartholomew, E.F., Petti, K.: Visual Anatomy and Physiology. Benjamin Cummings, Boston (2014)

48. Pavlov, Y. V, Rae, A., Bruce, R., Stout, H.P., Townend, P.P., Matto, A.R., Clegg, P.C.: Influence of Fiber Type and Moisture on Measured Fabric-to-Skin Friction. Paris (1990)

49. Wiertlewski, M., The, V., Hayward, V., Thonnard, J., Klo, A.: Physical factors influencing pleasant touch during tactile exploration. PLoS ONE 8, e0079085 (2013). https://doi.org/10.1371/ journal.pone. 0079085
50. Skedung, L., Danerlöv, K., Olofsson, U., Michael Johannesson, C., Aikala, M., Kettle, J., Arvidsson, M., Berglund, B., Rutland, M.W.: Tactile perception: finger friction, surface roughness and perceived coarseness. Tribol. Int. 44, 505-512 (2011). https://doi. org/10.1016/j.triboint.2010.04.010

51. Cesini, I., Ndengue, J.D., Chatelet, E., Faucheu, J., Massi, F.: Correlation between friction-induced vibrations and tactile perception during exploration tasks of isotropic and periodic textures. Tribol. Int. 120, 330-339 (2018). https://doi.org/10.1016/j.triboint.2017. 12.041

52. Sivamani, R.K., Maibach, H.I.: Tribology of skin. Proc. Inst. Mech. Eng. Part J 220, 729-737 (2006). https://doi.org/10.1243/ 13506501JET85

53. Man, G., Man, M.: Skin Friction Coefficient (2017)

54. Masen, M.A., Veijgen, N., Klaassen, M.: Experimental Tribology of Human Skin. In: Skin Biophysics, pp 281-295 (2019). https:// doi.org/10.1007/978-3-030-13279-8_10

55. Veijgen, N.K., Masen, M.A., Van Der Heide, E.: Relating friction on the human skin to the hydration and temperature of the skin. Tribol. Lett. 49, 251-262 (2013). https://doi.org/10.1007/ s11249-012-0062-1

56. Koudine, B.: Anthoine, Aubert, Lévêque: frictional properties of skin: Proposal of a new approach. Int. J. Cosmet. Sci. 22, 11-20 (2000). https://doi.org/10.1046/j.1467-2494.2000.00006.x

57. Groenendijk, M.N.W., Bana, V., Masen, M.A., van Kuilenburg, J., van der Heide, E.: An experimental study on the relation between surface texture and tactile friction. Tribol. Int. 48, 15-21 (2011). https://doi.org/10.1016/j.triboint.2011.06.003

58. Egawa, M., Oguri, M., Hirao, T., Takahashi, M., Miyakawa, M.: The evaluation of skin friction using a frictional feel analyzer. Ski. Res. Technol. 8, 41-51 (2002). https://doi.org/10.1034/j. 1600-0846.2002.080107.x

59. Gerhardt, L.C., Strässle, V., Lenz, A., Spencer, N.D., Derler, S.: Influence of epidermal hydration on the friction of human skin against textiles. J. R. Soc. Interface. 5, 1317-1328 (2008). https:// doi.org/10.1098/rsif.2008.0034

60. Nacht, S., Close, J.-A., Yeung, D., Gans, E.H.: Skin friction coefficient : changes induced by skin hydration and emollient application and correlation with perceived skin feel. J. Soc. Cosmet. Chem. 32, 55-65 (1981)

Publisher's Note Springer Nature remains neutral with regard to jurisdictional claims in published maps and institutional affiliations. 